\title{
Perirhinal Cortex Lesions Impair Context Aversion Learning
}

\author{
Dana J. Howse, Amanda S. Squires, Gerard M. Martin, and Darlene M. Skinner ${ }^{1}$ \\ Department of Psychology, Memorial University of Newfoundland, St. John's, NL, Canada A1B 3X9
}

\begin{abstract}
Rats with perirhinal cortex lesions were compared with sham controls on a conditional discrimination in which saccharin was paired with $\mathrm{LiCl}$ in context 1, but paired with saline in context 2. Perirhinal-lesioned rats were slightly slower to acquire the discrimination but reached control levels by the end of acquisition. Both groups showed transfer to familiar tap water, consuming less in context 1 than in context 2. Unlike sham rats, perirhinal rats failed to show an aversion to context 1 on a place choice test. These data provide neuroanatomical support for the postulated difference between Pavlovian conditioning and conditional learning.
\end{abstract}

Early studies revealed that when animals consume a novel solution and consequently become poisoned, they refuse to consume that solution when it is presented again (i.e., Revusky and Garcia 1970). Later studies revealed that these flavor aversions could be put under discriminative control by internal (drug-induced; Riley et al. 1989; Martin et al. 1990) and external contextual cues (Puente et al. 1988; Skinner et al. 1994b). Using a procedure modeled on occasion setting (Bouton and Swartzentruber 1986; Holland 1991; Rescorla 1991), Skinner et al. (1994b) trained rats to discriminate between two different contexts. In one context, a novel saccharin solution was paired with lithium chloride ( $\mathrm{LiCl})$. In a second context, the same saccharin solution was paired with a saline injection. Over the course of training, animals consumed significantly less saccharin in the first context relative to the second context.

The occasion-setting function of a stimulus is believed to be independent of direct associations between the cue and the US (Holland 1992). Skinner et al. (1994b) suggested that performance on their occasion-setting task with contextual cues was also not the result of an excitatory association, based on the fact that Pavlovian control groups given direct pairings of the context with $\mathrm{LiCl}$ did not show reliable suppression of fluid consumption. The investigators suggested that occasion setting was independent of Pavlovian conditioning even though both occasion setting and aversive context conditioning could be demonstrated in the same paradigm. For example, animals trained on the context discrimination task show suppression of fluid consumption in the context associated with LiCl (measure of occasion setting) and also avoid the context on a place choice test (measure of a Pavlovian association between the

${ }^{1}$ Corresponding author.

E-MAIL skinner@play.psych.mun.ca; FAX (709) 737-2430.

Article and publication are at http://www.learnmem.org/cgi/doi/ $10.1101 / \mathrm{lm} .57803$ context and $\mathrm{LiCl})$. Animals given direct pairings of the context with $\mathrm{LiCl}$ show the avoidance on the place choice test but do not show suppression of fluid consumption.

Behavioral probe tests have also revealed a distinction between Pavlovian conditioning and occasion setting. Using the discriminated taste aversion task, Martin et al. (1990) showed that a CS paired with $\mathrm{LiCl}$ blocked the formation of a taste aversion, whereas a conditional cue that modulated a saccharin-LiCl association failed to block the formation of a subsequent taste aversion. Extinction procedures, in which the contextual cues are presented with plain water, revealed that the occasion-setting function of a cue could be abolished, leaving the Pavlovian association between the cue and $\mathrm{LiCl}$ intact (Skinner et al. 1994). Recent unpublished data from our lab have shown that if the contextual cues are presented alone during extinction (i.e., no water or drinking response), then the Pavlovian aversion to the context is abolished, but discriminative control over saccharin consumption is not abolished.

If the Pavlovian conditioning system is distinct from the higher-order learning system (Holland 1992), then these systems might be further dissociated anatomically. Ross et al. (1984) showed that aspiration lesions of the hippocampus prevented the acquisition and retention of a conditional discrimination but not a Pavlovian conditioning task. However, Jarrard and Davidson (1990) performed neurotoxic lesions of the hippocampus and found that acquisition of a conditional discrimination task was not dependent on normal hippocampal functioning. Skinner et al. (1994a) found that ibotenic acid lesions of the hippocampus did not impair performance on the context discrimination task, but aspiration lesions of the hippocampus did impair performance. Rats with aspiration lesions of the hippocampus learned the context discrimination task more slowly than sham control rats, but the lesioned rats eventually reached control levels. Skinner et al. (1994a), like Jarrard and Dav-

LEARNING \& MEMORY 10:161-167 @ 2003 by Cold Spring Harbor Laboratory Press ISSN1072-0502/03 \$5.00

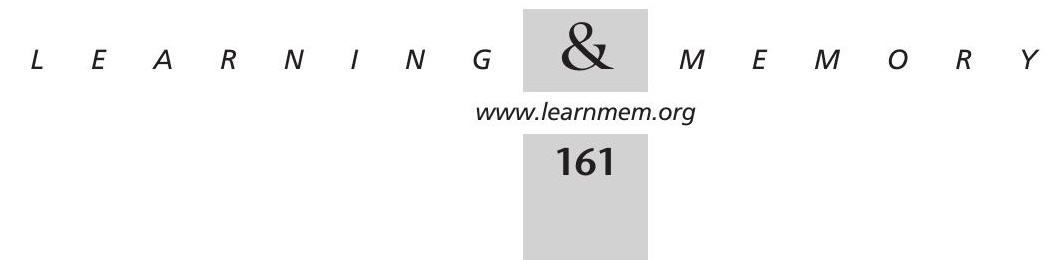


idson (1990), concluded that acquisition of conditional discriminations does not depend on an intact hippocampus. The larger impairment observed with aspiration lesions may have been due to extrahippocampal damage.

In recent years, a great deal of interest has been directed toward the mnemonic functions of the perirhinal cortex (Burwell et al. 1995; Suzuki 1996). The perirhinal cortex is a likely candidate for mediating associations between multiple cues and also for storage of information that might be acquired through various other memory systems. The perirhinal cortex provides many connections to the entorhinal cortex, which provides most of the cortical input to the dentate gyrus and hippocampus by means of the perforant pathway. The entorhinal cortex then projects back to the perirhinal cortex along with the unimodal association areas. In the rat, the perirhinal cortex receives mostly somatosensory, auditory, and olfactory input. The perirhinal cortex receives polymodal input via projections from the postrhinal cortex. The subcortical projections of the perirhinal cortex include the amygdala, striatum, and thalamus (Burwell et al. 1995), all of which have been implicated in various types of learning and memory (Stokes and Best 1988; Hunt and Aggleton 1991; McDonald and White 1993; Mumby et al. 1993; Salinas and White 1998).

Lesions of the perirhinal cortex in rats result in deficits in many types of learning (Bunsey and Eichenbaum 1993; Mumby and Pinel 1994; Wiig and Bilkey 1994; Herzog and Otto 1997; Otto et al. 1997; Liu and Bilkey 1998, 2001). Most relevant here are studies showing the effects of perirhinal cortex lesions on processing of contextual cues, particularly in fear conditioning paradigms. Corodimas and LeDoux (1995) showed that posttraining lesions of the rostral perirhinal cortex disrupted freezing to an auditory conditioned stimulus and to the conditioning context. The investigators suggested that the impairment in conditioning to the CS may have been the result of an effect of the lesions on contextual processing. They suggested that the perirhinal cortex may be involved in the use of contextual cues as retrieval aids. Similarly, posttraining inactivation of the perirhinal cortex in rats that had undergone CS and context conditioning revealed that freezing to both the CS and the context was impaired for up to $192 \mathrm{~h}$ (Sacchetti et al. 1999). However, other studies have failed to find an effect of perirhinal lesions on context conditioning (Phillips and LeDoux 1995; Herzog and Otto 1997). A recent study using a variety of lesion techniques and behavioral (fear conditioning) paradigms revealed that lesions of the perirhinal cortex disrupted context fear conditioning (Bucci et al. 2000).

The focus of the present experiment is the role of the perirhinal cortex in context discrimination learning. Given the role of the perirhinal cortex in aversive context conditioning, it seems likely that the perirhinal cortex might play a role in the context discrimination task previously used by Skinner et al. (1994a,b). Rats with bilateral aspiration le- sions of the perirhinal cortex and sham-lesioned rats were trained on a context discrimination task. This procedure establishes both contextual modulation over consummatory responding and context conditioning. The modulation of consummatory responding is measured using a transfer test in which a different flavor is substituted for the training flavor. The simple conditioning to the context is measured in a place choice test (Skinner et al. 1994a,b).

\section{RESULTS}

\section{Histology}

All of the lesioned rats had some damage to the perirhinal cortex. One rat had mostly unilateral damage and was removed from the analyses. Two other rats were removed because of damage to the external capsule, amygdala, and hippocampus. All of the remaining lesioned rats had extensive bilateral damage to the perirhinal cortex, with some sparing at the rostral and caudal extremes. All lesioned rats had some bilateral damage to temporal association cortex, as well as to ectorhinal and lateral entorhinal cortices (areas TeA, Ect, and LEnt according to Paxinos and Watson 1998). Six of the lesioned rats had damage encroaching on the ventral auditory cortex. The extent of extraperirhinal damage did not appear to be correlated with behavioral deficits. An examination of performance on the last cycle of discrimination training revealed that two lesioned rats did not consume substantially less on the danger day relative to the safe day. Of these two rats, one had extensive damage to the ectorhinal and lateral entorhinal cortices, whereas the second had minor damage to these areas. The rats with better discrimination performance had similar amounts of ectorhinal and lateral entorhinal damage. An examination of the place choice test data revealed that of the three rats with the biggest place aversion (i.e., good behavioral performance), two had extensive ectorhinal damage as well as lateral entorhinal damage. The other rat had minor damage to these areas. Figure 1 is a schematic drawing showing the largest and smallest perirhinal cortex lesions.

\section{Conditional Discrimination}

Saccharin consumption on the first three safe days was comparable in the two groups (Day 1: sham $=9.7( \pm 1.08) \mathrm{mL}$, lesioned $=9.4( \pm 1.41) \mathrm{mL}$; Day 2: sham $=10.8( \pm 1.08) \mathrm{mL}$, lesioned $=10.1( \pm 0.81) \mathrm{mL}$; Day 3: sham $=12.6( \pm 1.37) \mathrm{mL}$, lesioned $=11.5( \pm 0.76) \mathrm{mL}$. A two-way $($ Group $\times$ Days $)$ ANOVA revealed only a main effect of days $\left(F_{2,36}=7.40\right.$, $p<0.05)$.

Both sham and perirhinal-lesioned rats acquired the discrimination in the 20 cycles of training (Fig. 2). A three-way ANOVA (Group $\times$ Cycles $\times$ Context, safe or danger) over the entire acquisition phase revealed significant main effects of Group $\left(F_{1,360}=13.99, p<0.05\right)$, Cycles $\left(F_{19,360}=4.61\right.$, $p<0.05)$, and Context $\left(F_{1,360}=413.89, p<0.05\right)$, a signifi-

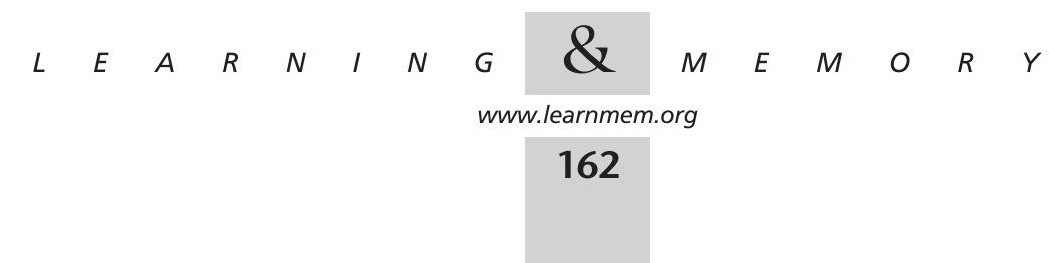




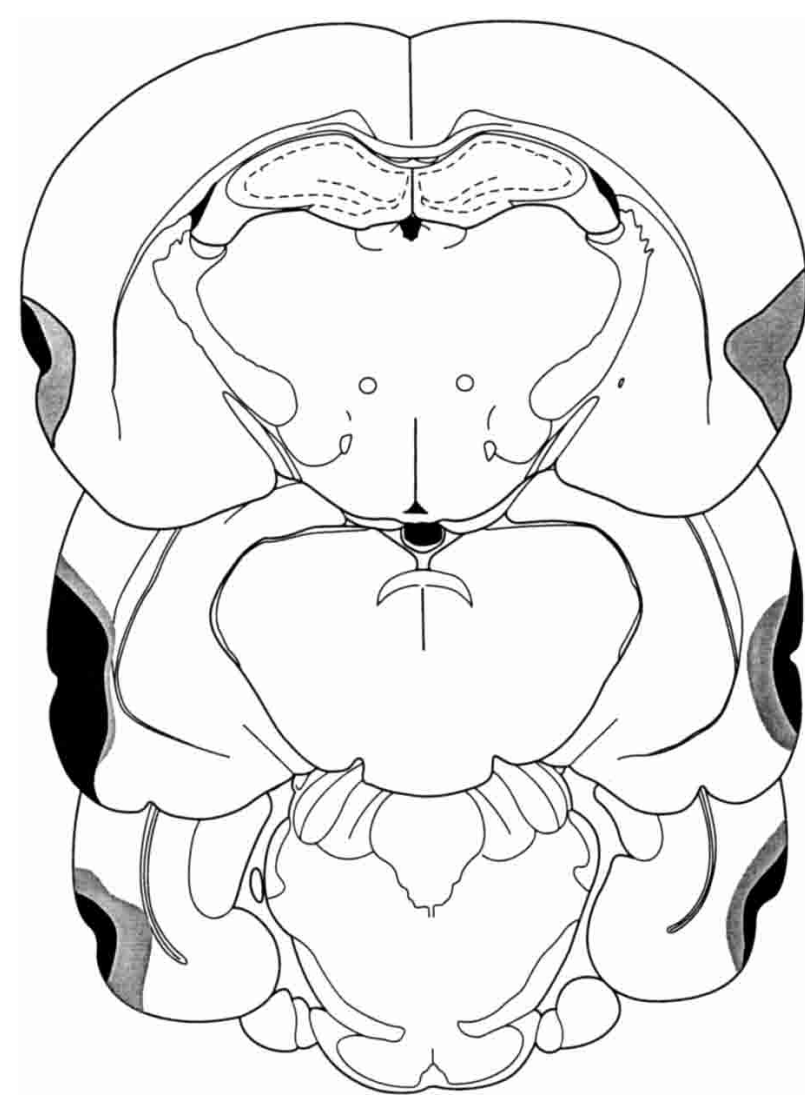

Figure 1 Schematic drawings of three coronal sections (AP from bregma $-6.80 \mathrm{~mm},-4.80 \mathrm{~mm}$, and $-2.80 \mathrm{~mm}$ ) of the largest (gray) and smallest (black) bilateral perirhinal lesions.

cant Group $\times$ Context interaction $\left(F_{1,360}=57.81, p<0.05\right)$, and a significant Cycles $\times$ Context interaction $\left(F_{19,360}=11.97\right.$, $p<0.05)$. The Cycles $\times$ Context interaction reflects the acquisition of the discrimination over the course of the 20 cycles. A followup Newman-Keuls test on the Group $\times$ Context interaction revealed that both sham- and perirhinal-lesioned rats consumed less saccharin in the danger context than in the safe context $\left(\phi_{\mathrm{s}}<0.05\right)$. The two groups consumed equal amounts in the danger context $(p>0.05)$, but the shamlesioned rats consumed more saccharin than did the perirhinal-lesioned rats in the safe context $(\phi<0.05)$.

Despite the lack of a significant three-way (Group $x$ Cycles $\times$ Context) interaction, the lesioned rats did appear to learn the discrimination at a somewhat slower rate than sham controls. Separate two-way ANOVAs (Group $\times$ Context) over each of the 20 cycles showed a significant Group $\times$ Context interaction for cycles $4,7,8$, $10,11,13$, and 17 . Thus, as early as cycle 4 , the shamlesioned rats were showing a significant discrimination, consuming less saccharin in the danger context than in the safe context. By the last three cycles, however, the shamand perirhinal-lesioned rats showed equivalent discrimination performance.

\section{Place Choice Test}

The perirhinal-lesioned rats, unlike sham rats, did not show an avoidance of the context that predicted $\mathrm{LiCl}$ (Fig. 3, top panel). A two-way ANOVA (Group $\times$ Context) revealed a significant Group $\times$ Context interaction $\left(F_{1,18}=8.65\right.$, $p<0.05)$. A followup Newman Keuls test revealed that sham-lesioned rats spent less time in the danger context relative to the safe context $(p<0.05)$. The perirhinallesioned rats, however, did not show a significant difference in the amount of time spent in the two contexts $(p>0.05)$.

\section{Tap Water Transfer}

A two-way (Group $\times$ Context) ANOVA on consumption during the transfer test revealed a main effect of Context only $\left(F_{1,181}=30.47, p<0.05\right)$. Both the perirhinal- and the sham-lesioned rats showed transfer to familiar tap water, consuming less tap water in the danger context than in the safe context (Fig. 3, bottom panel).

\section{DISCUSSION}

The present study revealed that sham- and perirhinallesioned rats acquired contextual control over saccharin consumption that transferred to consumption of familiar tap water on test. It was previously argued that context discrimination training results in modulation of fluid consumption in general rather than modulation of consumption of a specific flavor (Skinner et al. 1994a,b). The perirhinallesioned rats in the present study probably learned the task in the same manner as sham-lesioned rats, because both groups showed suppression of both saccharin and water consumption in the danger context. Unlike a previous study (Tassoni et al. 2000), there was no indication here that the perirhinal cortex is necessary for taste aversion learning. The lesioned rats suppressed consumption in the danger context, and throughout training there was no difference between the groups on danger trials. The Tassoni group used neural inactivation and found that disruption was limited to the early stages of taste information acquisition. There was no effect on the association of the taste with the US or in consolidation or retrieval.

The sham-lesioned rats showed a significant avoidance of the danger context on the place choice test. This aversion has also been demonstrated previously in rats trained on the context discrimination task and is indicative of a Pavlovian aversion to the danger context (Skinner et al. $1994 a, b)$. The aversion to the danger context does not appear solely to account for the discriminative fluid consumption, as rats given direct pairings of a context with $\mathrm{LiCl}$ do not show suppression of fluid consumption (Skinner et al. 1994b). The perirhinal-lesioned rats failed to show a significant avoidance of the danger context on the place choice test. Thus, the aversive properties of the context, as acquired through Pavlovian conditioning, do not appear to be necessary for conditional discrimination learning. The re-

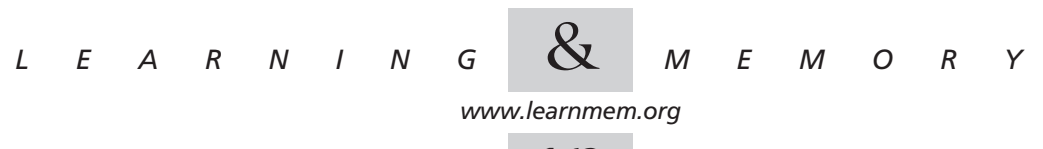




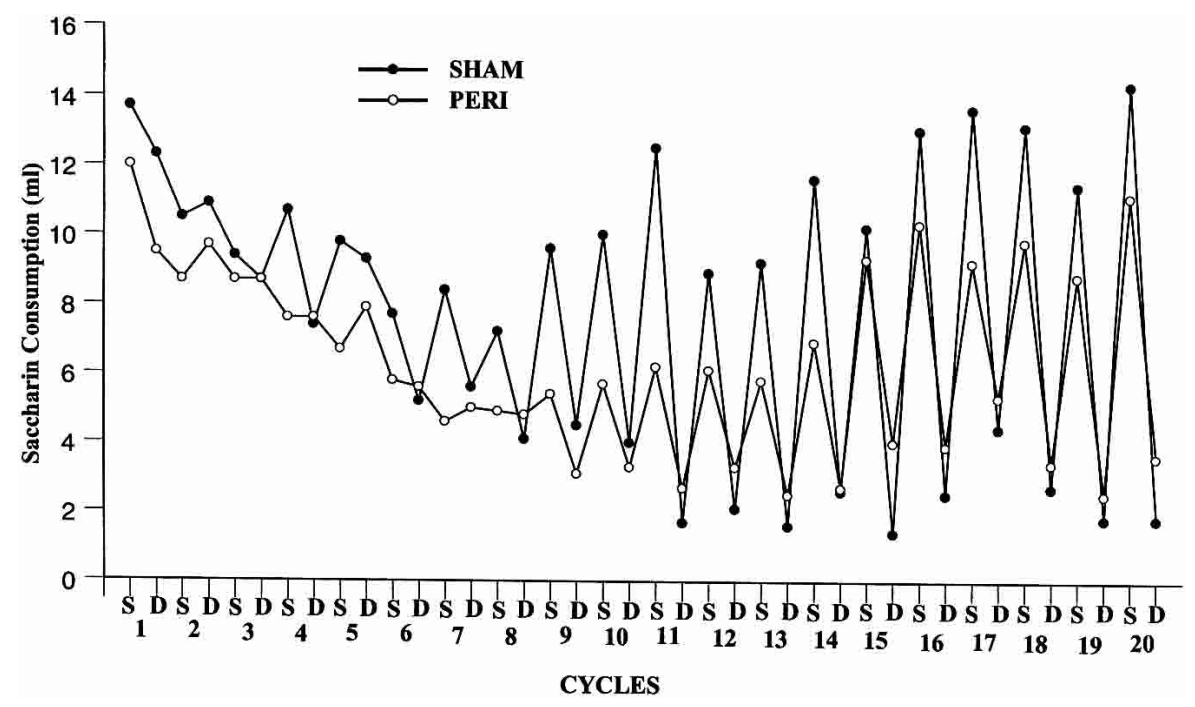

Figure 2 Mean (+SEM) saccharin consumption (in milliliters) by the perirhinal- and shamlesioned rats in the safe (S) and danger (D) contexts during the 20 cycles of context discrimination training.

sults provide neuroanatomical support for the distinction between conditional discrimination learning, or occasion setting, and simple Pavlovian conditioning that has been demonstrated behaviorally in several laboratories (Holland 1992; Skinner et al. 1994b).

The present results with perirhinal-lesioned rats are similar to those reported by Skinner et al. (2000) with amygdala-lesioned rats. Both amygdala- and sham-lesioned rats showed contextual control over saccharin consumption that transferred to a new fluid on test. However, rats with amygdala lesions did not show an aversion to the danger context on a place choice test. Thus, both amygdala- and perirhinal-lesioned rats were able to acquire a conditional discrimination, consuming less fluid in the danger context than in the safe context, but did not show a Pavlovian aversion to the danger context.

The perirhinal cortex and amygdala are closely related anatomically (Burwell et al. 1995), and both structures seem to play some role in fear conditioning. The amygdala is important for both contextual fear conditioning and fear conditioning to explicit CSs (Davis 1992; LeDoux 1993). The results with manipulations of the perirhinal cortex are mixed. Some have reported that the perirhinal cortex plays a role in contextual fear conditioning only (Bucci et al. 2000), whereas others have found it to be important for both contextual and CS fear conditioning (Sacchetti et al. 1999). It has been suggested that the perirhinal cortex acts as a connecting relay between amygdala and neocortex (Campeau and Davis 1995). Others argue against this possibility and suggest that the perirhinal cortex is more involved in memory storage and/or retrieval processes (Corodimas and LeDoux 1995; Sacchetti et al. 1999). It is not clear at present if connections between these two areas are critical or if they play independent roles in fear conditioning and context aversions.

The amygdala is important in the acquisition/expression of the emotional value of the context (LeDoux 1993). That is, conditioned fear to the context is only demonstrated in animals with an intact amygdala. The perirhinal cortex, like the amygdala, may also play a role in context conditioning. Alternatively, the perirhinal cortex may be more important for context discriminations. It has been suggested that the perirhinal (and postrhinal) cortex as well as the hippocampus play a role in discriminating between contextual cues (Frankland et al. 1998; Bucci et al. 2002). Frankland et al. (1998) argued that although the hippocampus is not critical for contextual fear conditioning, it is critical for context discrimination. They suggest that contextual- or cue-based strategies can be used to recognize an aversive context but that discrimination between contexts is acquired by hippocampal- (contextual-) based strategies. Similarly, Bucci et al. (2002) found that context discrimination was impaired by damage to the perirhinal or postrhinal cortices and suggested that both areas play a role in configural learning of contextual fear. The role of the perirhinal cortex in configural learning may be limited to tasks using contextual cues because rats with perirhinal cortex lesions exhibit intact negative patterning when visual and auditory cues are used (Bussey et al. 2000).

The deficit produced by the perirhinal lesions in the present study may be due to a difficulty in context discriminations when stimuli are presented simultaneously. During acquisition (where the lesioned rats were only slightly impaired) and during the transfer test (where the lesioned rats were identical to controls), only one context was presented on any given trial. During the place choice test (where the lesioned rats showed the biggest impairment), the animals were presented with both contexts and, for the first time, had to choose between them. Other work has demonstrated impaired discriminative performance in rats with perirhinal lesions when the stimuli are presented simultaneously (Otto and Garruto 1997).

The deficits on the place choice test by rats with perirhinal lesions may be due to a difficulty in parsing the testing context into the components used during training. During training, one context was reinforced (i.e., A+) while the second context was not reinforced (i.e., $\mathrm{B}-$ ). On the place choice test, the animals were presented with both contexts

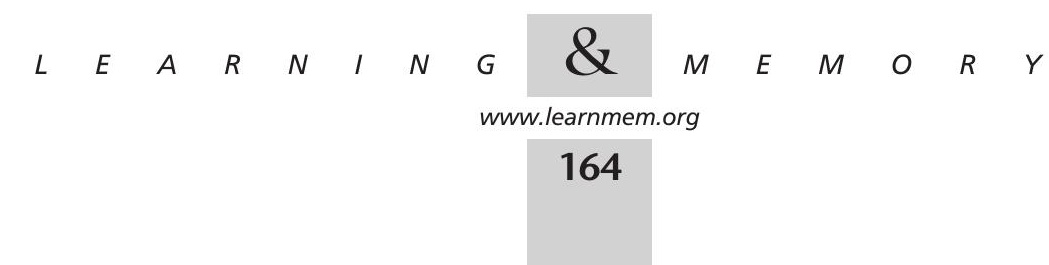



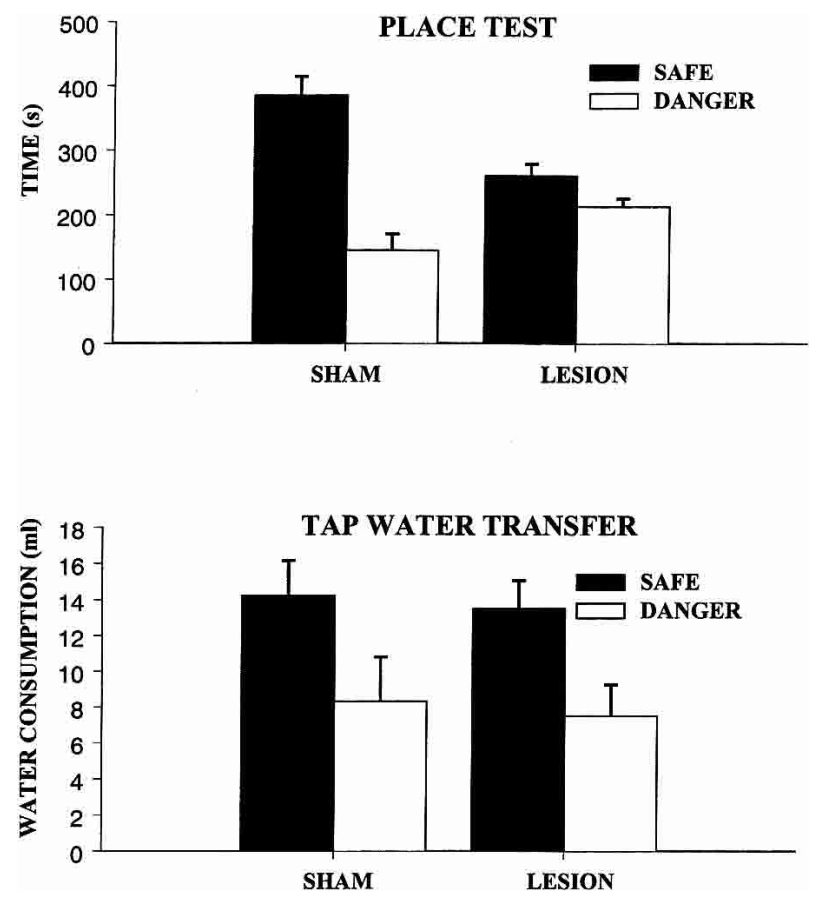

Figure 3 (Top panel) Mean (+SEM) time(s) spent in the safe (black) and danger (white) contexts during the 10-min choice test. (Bottom panel) Mean (+SEM) water consumption (in milliliters) by perirhinal- and sham-lesioned rats in the safe (black) and danger (white) contexts during the 2-d transfer test.

simultaneously $(\mathrm{AB})$. Control rats have little difficulty parsing the environment into its training components and choosing the safe (nonreinforced) side. In contrast, rats with perirhinal lesions spend equal time in both sides of the environment because the $\mathrm{AB}$ environment is an ambiguous stimulus with respect to $\mathrm{A}+$ or $\mathrm{B}-$ alone. Consistent with this interpretation is the observation that perirhinal lesions disrupt discriminations that involve ambiguous stimuli (Bussey et al. 2002).

The present study was conducted using animals with aspiration lesions of the perirhinal cortex. As a result, the impairment observed may be due to damage to fibers of passage through this region rather than to neuronal damage. Future studies will determine if the same pattern of results is obtained with neurotoxic lesions of the perirhinal cortex. However, lesions produced by different techniques and contextual conditioning assessed with different behavioral paradigms point to a role for the perirhinal cortex in contextual processing. Further study is necessary to determine the precise role of the perirhinal cortex in context conditioning and discrimination learning.

\section{MATERIALS AND METHODS}

\section{Subjects}

A total of 23 adult male Long-Evans rats, weighing 450-500 $\mathrm{g}$ at the beginning of behavioral training, were used. The rats underwent surgery within 1 to $2 \mathrm{wk}$ of their arrival in the laboratory. A water deprivation schedule consisting of 60 min access to tap water every afternoon was implemented $1 \mathrm{wk}$ before behavioral training. The rats had access to food at all times except during behavioral training trials.

\section{Surgery}

A total of 12 rats underwent aspiration lesions of the perirhinal cortex. Animals were anesthetized with avertin $(1 \mathrm{~mL} / 100 \mathrm{~g}$ of body weight) and placed in a head holder. After a scalp incision was made, the temporal muscle was cut and detached from the skull to expose the lateral surface. Holes were drilled in the skull to expose the rhinal sulcus. Aspiration was achieved with a glass pipette attached to a vacuum aspirator. After aspiration, the muscle was reattached with sutures. The 11 shams underwent the same procedure except no tissue was removed. Behavioral training commenced $\sim 2-3$ wk after surgery.

\section{Conditional Discrimination Training}

After recovery from surgery, rats were trained on a conditional discrimination task. This phase of the experiment consisted of safe and danger days. On danger days, rats were placed in a novel context for $15 \mathrm{~min}$ and then given access to a novel $0.1 \%$ saccharin solution for an additional $15 \mathrm{~min}$. The saccharin was removed and the rats were given an i.p. injection of $60 \mathrm{mg} / \mathrm{kg} \mathrm{LiCl}$ dissolved in $3 \mathrm{~mL}$ saline before being returned to their home cage. Safe days consisted of placing the rats in a second novel context for $15 \mathrm{~min}$ and then giving them $15 \mathrm{~min}$ access to the same saccharin solution. The rats were then given an i.p. injection of physiological saline and returned to their home cage. The training contexts were wooden boxes measuring $41 \times 41 \times 38 \mathrm{~cm}$. For half the rats, the danger context was a black box with a Plexiglass floor that was wiped with a $2 \%$ acetic acid solution before each trial. The safe context was a white box with a wire mesh floor covered with wood chips. These contextual cues were reversed for the other half of the rats. The rats were given four safe days at the beginning of training to familiarize them with the training context and the novel flavored saccharin solution. There were a total of 20 danger days with a varying number of safe days after each one. These extra safe days were given to all subjects to increase consumption in rats that developed a taste aversion. For the purposes of statistical analyses, this phase was divided into 20 cycles consisting of a danger day and the immediately preceding safe day. The extra safe days given between cycles were not analyzed.

\section{Place Choice Test}

After the 20th danger day, animals were given one final safe day. On the following day, all rats were given a place choice test. This test consisted of placing each rat in a neutral gray zone between the black and white training contexts. The amount of time, in seconds, spent in each of the two contexts was recorded for a 10-min period. No fluids were available during this test.

\section{Tap Water Transfer}

After the place test and a discrimination retention cycle, in which the rats were given a safe day followed by a danger day, a 2-d transfer test was carried out in which tap water was substituted for the saccharin solution. The rats were exposed to both training contexts, in a counterbalanced order, for $15 \mathrm{~min}$ before $15 \mathrm{~min}$ access to tap water. There were no injections given after the tap water was removed. After the 2-d transfer test, the rats were trained

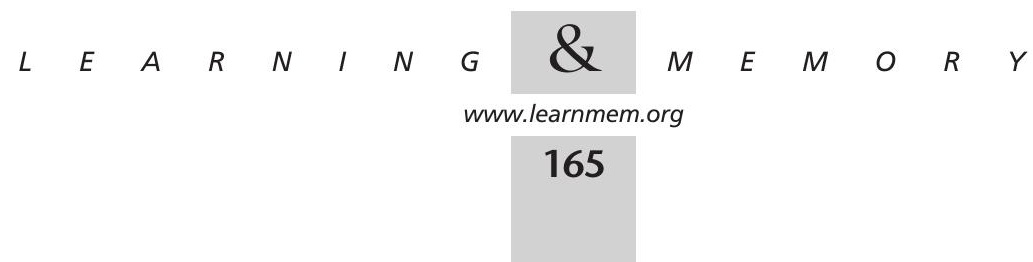


on a final discrimination cycle consisting of a safe day followed by a danger day.

\section{Histology}

After completion of behavioral testing, all rats were deeply anesthetized with Avertin and decapitated. Their brains were removed and submerged in methyl butane (that had been cooled in a $-70^{\circ} \mathrm{C}$ freezer) until frozen. The brains were then stored in a $-70^{\circ} \mathrm{C}$ freezer. To assess the location and extent of the lesions, 40- $\mu \mathrm{m}$ cryostat sections were cut, mounted on slides, and stained with cresyl violet.

\section{ACKNOWLEDGMENTS}

This study was supported by grants from the Natural Sciences and Engineering Council of Canada to D.M.S. and G.M.M. The authors thank Carolyn Harley for her assistance with the aspiration lesions.

The publication costs of this article were defrayed in part by payment of page charges. This article must therefore be hereby marked "advertisement" in accordance with 18 USC section 1734 solely to indicate this fact.

\section{REFERENCES}

Bouton, M.E. and Swartzentruber, D. 1986. Analysis of the associative and occasion-setting properties of contexts participating in Pavlovian discrimination. J. Exp. Psychol. Anim. Behav. Proc. 12: 333-350.

Bucci, D.J., Saddoris, M.P., and Burwell, R.D. 2001. Contextual fear discrimination is impaired by damage to the postrhinal or perirhinal cortex. Behav. Neurosci. 116: 479-488.

Bucci, D.J., Phillips, R.G., and Burwell, R.D. 2002. Contributions of postrhinal and perirhinal cortex to contextual information processing. Behav. Neurosci. 114: 882-894

Bunsey, M. and Eichenbaum, H. 1993. Critical role of the parahippocampal region for paired-associate learning in rats. Behav. Neurosci. 107: $740-747$.

Burwell, R.D., Witter, M.P., and Amaral, D.G. 1995. Perirhinal and postrhinal cortices of the rat: A review of the neuroanatomical literature and comparison with findings from the monkey brain. Hippocampus 5: 390-408

Bussey, T.J., Dias, R., Redhead, E.S., Pearce, J.M., Muir, J.L., and Aggleton, J.P. 2000. Intact negative patterning in rats with fornix or combined perirhinal and postrhinal cortex lesions. Exp. Brain. Res. 134: 506-519.

Bussey, T.J., Saksida, L.M., and Murray, E.A. 2002. Perirhinal cortex resolves feature ambiguity in complex visual discriminations. Eur. $J$. Neurosci. 15: 365-374.

Campeau, S. and Davis, M. 1995. Involvement of subcortical and cortica afferents to the lateral nucleus of the amygdala in fear conditioning measured with fear-potentiated startle in rats trained concurrently with auditory and visual conditioned stimuli. J. Neurosci. 15: 2312-2327.

Corodimas, K.P. and LeDoux, J.E. 1995. Disruptive effects of posttraining perirhinal cortex lesions on conditioned fear: Contributions of contextual cues. Behav. Neurosci. 109: 613-619.

Davis, M. 1992. The role of the amygdala in fear and anxiety. Ann. Rev. Neurosci. 15: 353-375.

Frankland, P.W., Cestari, V., Filipkowski, R.K., McDonald, R.J., and Silva, A.J. 1998. The dorsal hippocampus is essential for context discrimination but not for contextual conditioning. Behav. Neurosci. 112: $863-874$.

Herzog, C. and Otto, T. 1997. Odor-guided fear conditioning in rats. II. Lesions of the anterior perirhinal cortex disrupt fear conditioned to the explicit conditioned stimulus but not to the training context. $J$. Neurosci. 111: 1265-1272.

Holland, P.C. 1991. Acquisition and transfer of occasion setting in operant feature positive and feature negative discriminations. Learn. Motiv. 22: $366-387$
1992. Occasion setting in Pavlovian conditioning. In The psychology of learning and motivation (ed. D. Medin), Vol. 28, pp. 69-125. Academic Press, San Diego, CA.

Hunt, P.R. and Aggleton, J.P. 1991. Medial dorsal thalamic lesions and working memory in the rat. Behav. Neur. Biol. 55: 227-246.

Jarrard, L.E. and Davidson, T.L. 1990. Acquisition of concurrent conditional discriminations in rats with ibotenate lesions of hippocampus and of subiculum. Psychobiology 18: 68-73.

LeDoux, J.E. 1993. Emotional memory systems in the brain. Behav. Brain Res. 58: 69-79.

Liu, P. and Bilkey, D.K. 1998. Perirhinal cortex contributions to performance in the Morris water task. Behav. Neurosci. 112: 304-315.

. 2001. The effect of excitotoxic lesions centered on the hippocampus or perirhinal cortex in object recognition and spatial memory tasks. Behav. Neurosci. 115: 94-111.

Martin, G.M., Gans, M., and van der Kooy, D. 1990. Discriminative properties of morphine that modulate associations between tastes and lithium chloride. J. Exp. Psychol. Animal Behav. Proc. 16: 56-68.

McDonald, R.J. and White, N.M. 1993. A triple dissociation of memory systems: Hippocampus, amygdala, and dorsal striatum. Behav. Neurosci. 107: 3-22

Mumby, D.G. and Pinel, J.P.J. 1994. Rhinal cortex lesions and object recognition in rats. Behav. Neurosci. 108: 11-18.

Mumby, D.G., Pinel, J.P.J., and Dastur, F.N. 1993. Mediodorsal thalamic lesions and object recognition in rats. Psychobiology 21: 27-36.

Otto, T. and Garruto, D. 1997. Rhinal cortex lesions impair simultaneous olfactory discrimination learning in rats. Behav. Neurosci 111: $1146-1150$

Otto, T., Wolf, D., and Walsh, T.J. 1997. Combined lesions of perirhinal and entorhinal cortex impair rats' performance in two versions of the spatially guided radial-arm maze. Neurobiol. Learn. Mem. 68: 21-31.

Paxinos, G. and Watson, C. 1998. The rat brain in stereotaxic coordinates. Academic Press, New York, NY.

Phillips, R.G. and LeDoux, J.E. 1995. Lesions of the fornix but not the entorhinal or perirhinal cortex interfere with contextual fear conditioning. J. Neurosci. 15: 5308-5315.

Puente, G.P., Cannon, D.S., Best, M.R., and Carrell, L.E. 1988. Occasion setting of fluid ingestion by contextual cues. Learn. Motiv 19: $239-253$.

Rescorla, R.A. 1991. Separate reinforcers can enhance the effectiveness of modulators. J. Exp. Psychol. Anim. Behav. Proc. 17: 239-269.

Revusky, S. and Garcia, J. 1970. Learned associations over long delays. In Psychology of learning and motivation: Advances in research and theory (eds. G. Bower and J. Spence), Vol. 4, pp. 1-83. Academic Press, New York, NY.

Riley, A.R., Jeffreys, R.D., Pournaghash, S., Titley, T.L., and Kufera, A.M 1989. Conditioned taste aversions as a behavioral baseline for drug discrimination learning: Assessment with the dipsogenic compound pentobarbital. Drug Dev. Res. 16: 229-236.

Ross, R.T., Orr, W.B., Holland, P.C., and Berger, T.W. 1984 Hippocampectomy disrupts acquisition and retention of learned conditional responding. Behav. Neurosci. 98: 211-225.

Sacchetti, B., Lorenzini, C.A., Baldi, E., Tassoni, G., and Bucherelli, C. 1999. Auditory thalamus, dorsal hippocampus, basolateral amygdala, and perirhinal cortex role in the consolidation of conditioned freezing to context and to acoustic conditioned stimulus in the rat. J. Neurosci. 19: $9570-9578$

Salinas, J.A. and White, N.M. 1998. Contributions of the hippocampus, amygdala, and dorsal striatum to the response elicited by reward reduction. Behav. Neurosci. 112: 812-826.

Skinner, D.M., Martin, G.M., Harley, C., Kolb, B., Pridgar, A., Bechara, A., and van der Kooy, D. 1994a. Acquisition of conditional discriminations in hippocampal lesioned and decorticated rats: Evidence for learning that is separate from both simple classical conditioning and configural learning. Behav. Neurosci. 108: 911-926.

Skinner, D.M., Martin, G.M., Pridgar, A., and van der Kooy, D. 1994b. Conditional control of fluid consumption in an occasion setting

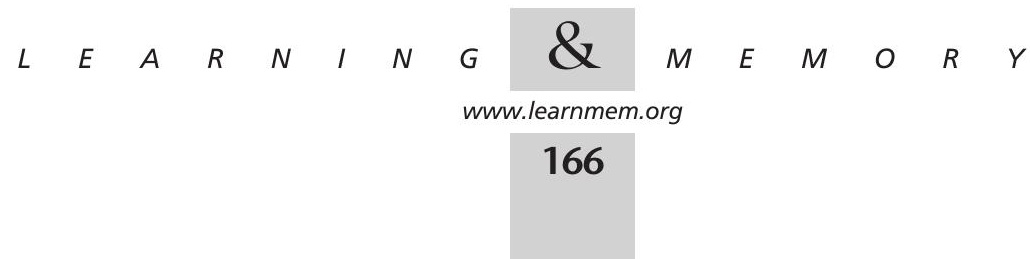


paradigm is independent of Pavlovian associations. Learn. Motiv. 25: 368-400.

Skinner, D.M., Clarke, H.A., and van der Kooy, D. 2000. Amygdala lesions impair context aversions but not the ability of contexts to serve as occasion setters. Psychobiology 28: 67-80.

Stokes, K.A. and Best, P.J. 1988. Mediodorsal thalamic lesions impair radial maze performance in the rat. Behav. Neurosci. 102: 294-300.

Suzuki, W.A. 1996. The anatomy, physiology and functions of the perirhinal cortex. Curr. Opin. Neurobiol. 6: 179-186.
Tassoni, G., Lorenzini, C.A., Baldi, E., Sacchetti, B., and Bucherelli, C. 2000. Role of the perirhinal cortex in rats' conditioned taste aversion response memorization. Behav. Neurosci. 114: 875-881.

Wiig, K.A. and Bilkey, D.K. 1994. Effects of perirhinal cortex lesions on spatial reference memory in the rat. Behav. Brain Res. 63: 101-109.

Received November 11, 2002; accepted in revised form March 19, 2003.

$\begin{array}{llllllllllllllllllllllllllll} & E & A & R & N & I & N & G & \bigotimes & M & E & M & O & R & Y\end{array}$ www.learnmem.org 


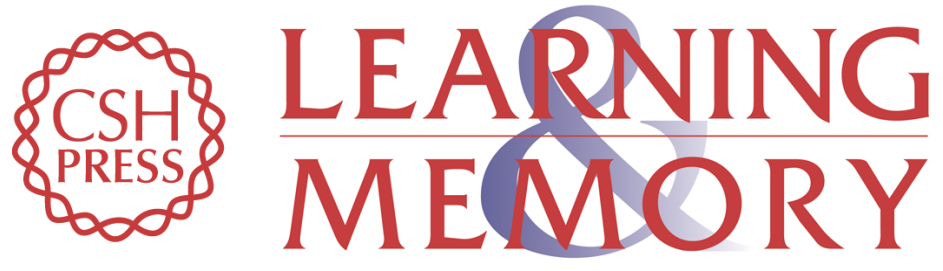

\section{Perirhinal Cortex Lesions Impair Context Aversion Learning}

Dana J. Howse, Amanda S. Squires, Gerard M. Martin, et al.

Learn. Mem. 2003, 10:

Access the most recent version at doi:10.1101/lm.57803

References This article cites 35 articles, 3 of which can be accessed free at: http://learnmem.cshlp.org/content/10/3/161.full.html\#ref-list-1

License

Email Alerting Receive free email alerts when new articles cite this article - sign up in the box at the Service top right corner of the article or click here. 